\title{
Nematicidal effect of chestnut tannin solutions on the potato cyst nematode Globodera rostochiensis (Woll.) Barhens
}

\author{
M. RENČO ${ }^{1 *}$, N. SASANELLI ${ }^{2}$, I. PAPAJOVÁ ${ }^{1}$, L. MAISTRELLO $^{3}$
}

\author{
1*Parasitological Institute of Slovak Academy of Sciences, Hlinkova 3, 04001 Košice, \\ Slovak Republic, E-mail: renco@saske.sk; ${ }^{2}$ Institute for Plant Protection, C.N.R., Via G. Amendola 122/D, 70126 \\ Bari, Italy, E-mail: n.sasanelli@ba.ipp.cnr.it; ${ }^{3}$ Department of Agricultural and Food Sciences, University of Modena \\ and Reggio Emilia, Area S. Lazzaro, Pad. Besta, Via G. Amendola 2, 42122 Reggio Emilia, Italy. \\ E-mail: lara.maistrello@unimore.it
}

\begin{abstract}
Summary
Recently, tannins have been reported for their nematicidal activity against the root-knot nematode Meloidogyne javanica both in vitro and in pot experiments in addition to a biocidal effect on a wide range of fungi, bacteria and yeasts. However, no information is available on the effect of these polyphenols on plant parasitic cyst nematodes. Therefore, an in vitro and a pot experiments on potato were undertaken to investigate the nematicidal activity of tannin aqueous solutions at different concentrations on the potato cyst nematode Globodera rostochiensis. In the in vitro experiment different tannin concentrations in a geometric scale (from 0.32 to $20.48 \mathrm{~g} / \mathrm{l}$ ) were tested for their effect on the egg hatch of the nematode. All tested tannin concentrations were effective to reduce egg viability from 56 to $87 \%$, in comparison to the untreated control. In the pot experiment, tannins, as aqueous solutions at rates of 100 , 250 and $450 \mathrm{~g} / \mathrm{m}^{2}$, were applied to soil at two different application times (at sowing and at sowing and two weeks later). All tested doses were effective to reduce the number of cyst/100 g soil, eggs and juveniles/g soil and reproduction rate in comparison to untreated control. The number of eggs and juveniles/cyst was not influenced by the different applied rates of tannins.
\end{abstract}

Keywords: golden nematode; nematode control; polyphenols; Castanea sativa $\mathrm{L}$.

\section{Introduction}

The golden nematode, Globodera rostochiensis (Woll.) Barhens causes severe yield losses in many potato growing areas of the world (Anand et al., 1998). The extent of yield loss is related to the nematode population density in the soil, which should be always maintained below the estimated damage threshold (1.9 eggs and juveniles/g soil) (Greco et al., 1982; Sasanelli, 1994). G. rostochiensis is a quarantine pest included in the part A of the section II of the Annex 1 of the EU Directive 29/2000 (harmful organisms known to occur in the Community and relevant for the entire Community) and in the quarantine list of phytoparasitic nematodes in Europe, A1 list, of the European and Mediterranean Plant Protection Organization (EPPO). Soil treatments with nematicides in different formulations (fumigants, granulars or liquids) can successfully and economically control G. rostochiensis (Greco et al., 1984; Been \& Schomaker, 1999). However, the recent European Legislation (Reg. CE 396/2005; 1095/2007; 33/2008; $299 / 2008$ and 1107/2009) has deeply restricted and revised the use of pesticides on agricultural crops focusing the attention on enviromental safety, human and animal health. Therfore, research on low environmental impact alternatives to chemicals has received a stronge impulse with a wide range of options. Among the alternatives are soil solarization (McSorley \& McGovern, 2000), organic amendments (Renčo et al., 2007, 2011; Hu \& Qi, 2010; D'Addabbo et al., 2011; Toden et al., 2011), biofumigation (Aires et al., 2009), mycorrhization (Ryan \& Jones, 2004; Sasanelli et al., 2007, 2009) or, more recently, natural plant-derived compounds (Céspedes et al., 2006). In particular, plants may represent a source of natural nematicide, as a higher number of nematicidal compounds are already reported in many species (Chitwood, 2002). Commercial formulations based on plant-derived extracts of (Quillaja saponaria Molina), marigold (Tagetes erecta L.) and neem (Azadirachta indica Juss) are already available. Tannins, natural products extracted from many plants, have been reported to possess antihelmintic activity especially for gastrointestinal nematodes in ruminants (Hoste et al., 2006). They are secondary plant polyphenols whose chemical and physical properties can change according to the plants (i.e. Castanea sativa Miller or Schinopsis lorentzii (Schldl.) Barkley \& Meyer, etc.), parts of the plants and the season in which they are produced (Waterman, 1999; Waghorn \& McNabb, 2003). Moreover, tannins protect several plants against 
herbivores (Feeny, 1976) and are toxic to a wide range of fungi, bacteria and yeasts (Scalbert, 1991).

Recently, tannins have been reported for their nematicidal activity against the root-knot nematode Meloidogyne javanica (Treub) Chitw. both in vitro and in pot experiments (Maistrello et al., 2010). However, there is no information on the effect of these polyphenols on plant parasitic cyst nematodes. Therefore, an in vitro and a pot experiments were undertaken to investigate the nematicidal activity of tannin aqueous solutions at different concentrations on the potato cyst nematode $G$. rostochiensis.

\section{Materials and methods}

\section{Hatching test}

The population of Globodera rostochiensis, previously identified as pathotype Ro1, was obtained from an infested soil at Avezzano (province of L'Aquila, Italy). The cysts were collected by Fenwick can from dried soil. Batches of 50 cysts of similar size (about 115 eggs and juveniles/cyst) were placed in $2 \mathrm{~cm}$ diam sieves $(215 \mu \mathrm{m}$ aperture). Each sieve was put in a $3.2 \mathrm{~cm}$ diam Petri dish (Shepherd, 1986) and all dishes were arranged according to a complete randomised block design in a growth cabinet at $20 \pm 2{ }^{\circ} \mathrm{C}$ (Ekanayake \& Di Vito, 1984) with four replicates for each treatment.

The tannins were provided by Agrostar s.r.l. (Cavriago, province of Reggio Emilia, Italy) and they were extracted by vapour from chestnut wood, without chemical solvents, in powder form after dehydration. Different concentrations from 0.32 to $20.48 \mathrm{~g} / \mathrm{l}$, in a geometric series, were obtained by dissolving the largest rate of tannin in distilled water (Table 1). Each tested aqueous tannin solution was prepared considering a double concentration, because each of them was adjusted with an equal amount of potato root leachate used as natural hatching agent.

Four $\mathrm{ml}$ of each test solution, sufficient to cover cysts, were then added to four batches of cysts. Potato root leachate, which was used as control, was collected from three month-old actively growing potato plants, cultivated in fifteen $2,500 \mathrm{~cm}^{3}$ clay pots, by drenching the soil with excess tap water. The leachate was then centrifuged at 1,300 rpm for 15 minutes, stored in plastic bottles, and kept in a freezer until required. Only small amounts were kept in a refrigerator at $5{ }^{\circ} \mathrm{C}$ for immediate use.

Juveniles $\left(\mathrm{J}_{2}\right)$ emerging from cysts were removed and counted every week over a 12 week period. The solutions were renewed weekly but after four weeks the test solutions were removed and for the remaining eight more weeks the incubation continued only in potato root leachate, according to an already described methodology (Sasanelli \& Di Vito, 1991; Sasanelli \& D'Addabbo, 1992) (Table 1). At the end of the experiment cysts were crushed according to Seinhorst and Den Ouden (1966), and unhatched eggs and juveniles were counted. Numbers of second stage juveniles emerging weekly were expressed as cumulative percentages of the total egg content of the cysts (hatched + unhatched eggs).
Data were subjected to analysis of variance (ANOVA), after arc sin square root transformation (Bliss' Tables), and means were compared by Least Significant Difference's Test. All statistical analyses were performed using the PlotIT program. The Abbott's formula (Abbott, 1925) was used to calculate the mortality of eggs in tannin treated cysts at the different tested concentrations.

\section{Glasshouse experiment}

The same population of $G$. rostochiensis used in the in vitro experiment was also used for the pot experiment carried out in glasshouse. The cysts were extracted from an infested field (Avezzano, AQ) and thoroughly mixed into $2.9 \mathrm{~kg}$ steam sterilised sandy soil. Ten $10 \mathrm{~g}$ soil samples were taken from this inoculum and the cysts were extracted, counted and their egg content estimated. Appropriate amounts $(100 \mathrm{~g})$ of this inoculum were then thoroughly mixed with the steam sterilised soil in each clay pot containing 3,900 $\mathrm{g}$ soil to give an initial nematode population density of 5 eggs and juveniles/g soil. The pots were arranged on benches in a glasshouse at $23 \pm 2{ }^{\circ} \mathrm{C}$ according to a randomized block design with four replicates for each treatment. Three tannin concentrations were considered 1) $100 \mathrm{~g} / \mathrm{m}^{2}$; 2) $250 \mathrm{~g} / \mathrm{m}^{2}$ and 3) $450 \mathrm{~g} / \mathrm{m}^{2}$, applied only at sowing or at sowing and two weeks later, for a total of six tannin treatments (Table 2). Nematode infested untreated soil was used as control. Tannins were applied as aqueous solutions $(1,400 \mathrm{ml} /$ pot $)$, calibrated on the holding capacity of the soil.

After inoculation, to all clay pot one potato tuber (cv. Désirée) was planted. During the experiment potato plants were maintained in the glasshouse randomizing the position of the blocks and at the same time repositioning each plant within a block every week, to avoid a block position effect and at the same time the factor position of the plant within the block. Plants received all the necessary maintenance (irrigation, fertilization, etc.).

Three months later, at the end of the experiment, potato plants were uprooted and fresh and dry top and root weight and height were recorded. Soil from each pot was mixed thoroughly and then a soil sample was collected and air dried. Cysts were extracted by Fenwick can from $200 \mathrm{~g}$ sub-sample, crushed (Seinhorst \& Den Ouden, 1966) and their egg content estimated.

Data from the experiment were subjected to analysis of variance (ANOVA) and means compared by Least Significant Difference's Test. Statistical analysis were performed using the PlotIT program. TableCurve program was used to analyze the relationships between different tannin doses and nematological parameters of the potato cyst nematode.

\section{Results}

\section{Hatching test}

During the first week, nematode hatch in the untreated control was significantly higher than all other treatments with tannin aqueous solutions at different concentration 


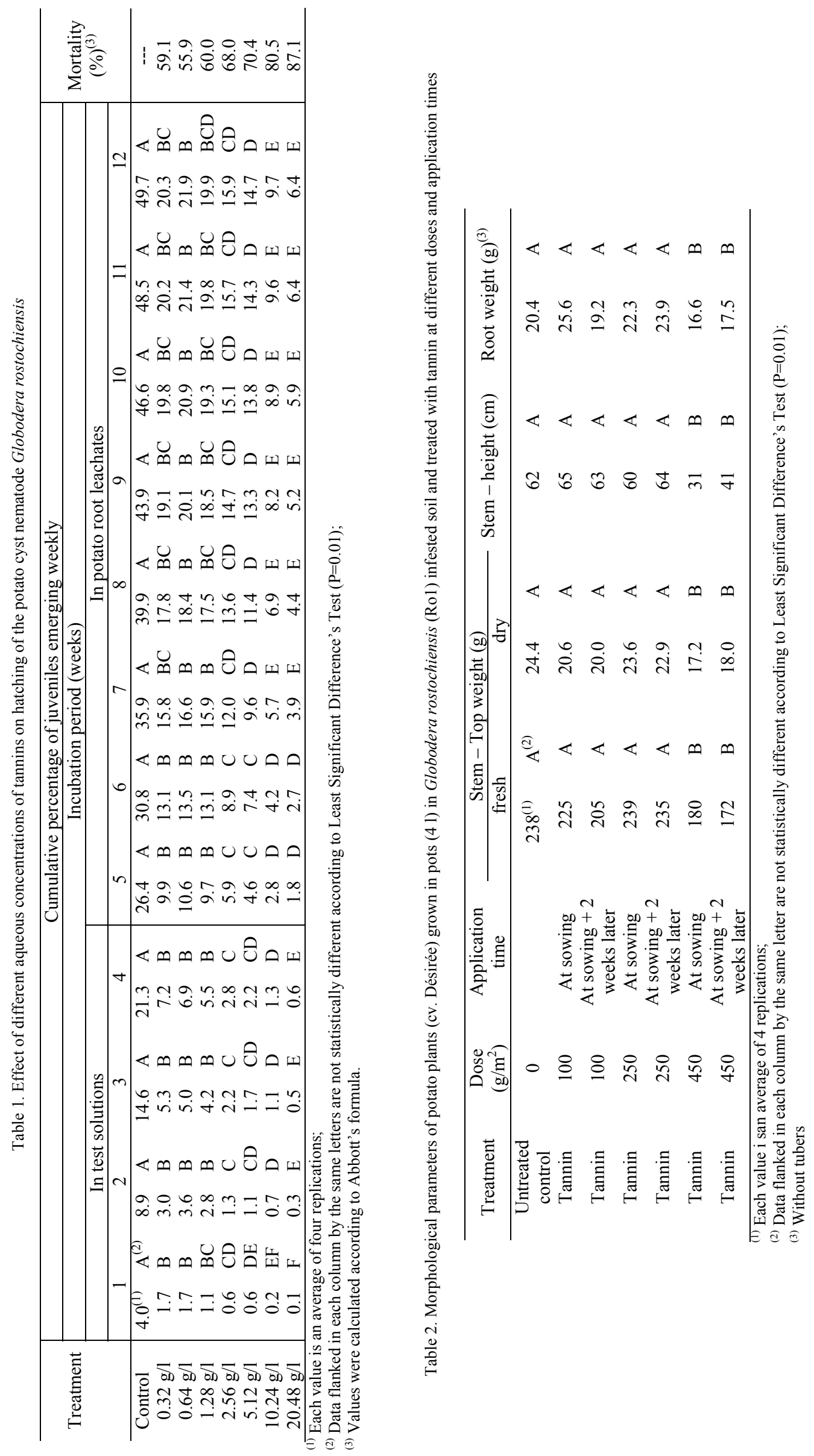


(Table 1). The highest per cent hatch reduction $(0.1 \%)$ was observed at the concentration of $20.48 \mathrm{~g} / \mathrm{l}$ tannin solution, although this percentage was no statistically different from the one recorded at $10.24 \mathrm{~g} / \mathrm{l}$ tannin concentration (Table 1). During the first four weeks, emergence of juveniles from $G$. rostochiensis cysts was suppressed in all tannin aqueous solutions. All treatments with tannins in the range 0.32 $1.28 \mathrm{~g} / \mathrm{l}$ did not significantly differ among each other (Table 1). Moreover, no significant difference was observed between tannin treatments at 2.56 and $5.12 \mathrm{~g} / \mathrm{l}$. From the second week until the fourth week the percent hatch of juveniles from cysts treated with tannin at the highest
(Table 3). The highest reduction of these parameters was recorded in tannin treatment at dose of $450 \mathrm{~g} / \mathrm{m}^{2}$ applied at sowing and at sowing and 2 weeks later, although this treatment was not significantly different from that at the same dose applied only at sowing and that at $250 \mathrm{~g} / \mathrm{m}^{2}$ applied two times (Table 3 ). The tannin treatments at different doses did not significantly affect the number of eggs/cyst (Table 3). No significant differences, in all nematological parameters, were found between the tannin applications at sowing and at sowing and 2 weeks later for all the three tested concentrations (100, 250 and $\left.450 \mathrm{~g} / \mathrm{m}^{2}\right)$ (Table 3).

Table 3. Nematological parameters of potato plants (cv. Désirée) grown in pots (4 1) in Globodera rostochiensis (Ro1) infested soil and treated with tannin at different doses and application times.

\begin{tabular}{|c|c|c|c|c|c|c|c|c|c|c|}
\hline Treatment & $\begin{array}{c}\text { Dose } \\
(\mathrm{g} / \mathrm{m} 2)\end{array}$ & Application time & $\begin{array}{r}\text { Numbe } \\
\text { cysts/100 }\end{array}$ & $\begin{array}{l}\text { of } \\
\text { soil }\end{array}$ & Eggs and & cyst & \multicolumn{2}{|c|}{ Eggs and $\mathrm{J}_{2} / \mathrm{g}$ soil } & \multicolumn{2}{|c|}{$r=P f / P i$} \\
\hline Untreated control & 0 & & $78.8^{(1)}$ & $\mathrm{A}^{(2)}$ & 150 & $\mathrm{~A}$ & 118.0 & A & 23.6 & A \\
\hline Tannin & 100 & At sowing & 23.5 & $\mathrm{BC}$ & 172 & A & 40.6 & $\mathrm{~B}$ & 8.1 & B \\
\hline Tannin & 100 & At sowing +2 weeks later & 30.5 & B & 138 & A & 41.0 & $\mathrm{BC}$ & 8.2 & $\mathrm{BC}$ \\
\hline Tannin & 250 & At sowing & 20.5 & $\mathrm{BC}$ & 174 & A & 36.4 & $\mathrm{BC}$ & 7.3 & $\mathrm{BC}$ \\
\hline Tannin & 250 & At sowing +2 weeks later & 17.5 & $\mathrm{CD}$ & 141 & A & 24.4 & $\mathrm{CD}$ & 4.9 & $\mathrm{CD}$ \\
\hline Tannin & 450 & At sowing & 12.5 & $\mathrm{CD}$ & 130 & A & 16.2 & $\mathrm{D}$ & 3.2 & $\mathrm{D}$ \\
\hline Tannin & 450 & At sowing +2 weeks later & 8.0 & $\mathrm{D}$ & 141 & A & 11.0 & $\mathrm{D}$ & 2.2 & $\mathrm{D}$ \\
\hline
\end{tabular}

(1) Each value is an average of 4 replications;

${ }^{(2)}$ Data flanked in each column by the same letter are not statistically different according to Least Significant Difference's Test ( $\left.\mathrm{P}=0.01\right)$;

concentration $(20.48 \mathrm{~g} / \mathrm{l})$ was significantly lower than that observed at $10.24 \mathrm{~g} / 1$ (Table 1$)$.

When tannin aqueous solutions were removed and the incubation continued in potato root leachate, the emergence of juveniles increased in all treatments, although it remained significantly lower than in the control until the end of the experiment (Table 1). In general, in each week between the fifth and the seventh week, no significant statistical differences were observed in the percentage of hatch in cysts treated in aqueous tannin solutions in the ranges of $0.32-1.28,2.56-5.12$ and $10.24-20.48 \mathrm{~g} / 1$ concentrations (Table 1). Statistical differences were significantly more evident in the incubation period between the eighth and the twelfth week. At the end of the experiment, percent mortality of eggs from cysts treated with tannin solutions ranged between 55.9 and 87.1 (Table 1). The lowest and the highest percentage of egg mortality were detected at 0.64 and $20.48 \mathrm{~g} / \mathrm{l}$ tannin concentration, respectively.

\section{Glasshouse experiment}

All treatments with tannin did not significantly $(P=0.01)$ increase potato plants growth variables (top fresh and dry stem and root weights and stem height) compared with the untreated control (Table 2). However, treatments with the highest dose of tannin $\left(450 \mathrm{~g} / \mathrm{m}^{2}\right)$ applied at sowing and again 2 weeks later, significantly reduced plant growth in comparison to the lower applied doses and to the inoculated and untreated control (Table 2).

The number of G. rostochiensis cysts/100 g soil, the number of eggs and second stage juveniles/g soil and the reproduction rate $(r=P f / P i)$ were significantly reduced by all tannin treatments in comparison to the untreated control
Based on the results, significant negative correlations were found in the relationship between the four different applied doses, including the control, and the values of the number of cysts/100 g soil, eggs and juveniles/g soil and " $r$ " (Fig. 1). The equations reasonably explain the above relationships, as indicated by the high values of the correlation coefficients $\left(r^{2}\right)$ (Fig. 1).

\section{Discussion and Conclusions}

Studies on the effect of tannins on plant parasitic nematodes are few, whereas the studies on tannins as suppressant of gastrointestinal nematodes, bacteria and yeasts are numerous (Scalbert, 1991; O'Donovan \& Brooker, 2001; Paolini et al., 2003; Nguyen et al., 2005; Elizondo et al., 2010). In our in vitro experiment, chestnut tannin solutions significantly reduced $G$. rostochiensis egg hatch during the first fourth weeks in comparison to untreated control. Also, when tannin aqueous solutions were removed and the incubation continued in potato root leachate, the emergence of juveniles remained significantly lower compared to the untreated control until the end of the experiment demonstrating a nematicidal effect of these solutions. Similar results, using the same chestnut tannin at the same concentrations in an in vitro experiment, were found on the root-knot nematode Meloidogyne javanica (Treub) Chitwood by Maistrello et al. (2010). Also Chen et al. (1997) found a suppressive effect on egg hatch of the soybean cyst nematode Heterodera glycines in in vitro experiment with tannic acid extracted from tara Caesalpinia spinosa (Molina) Kuntze applied at concentrations between 0.156 and $10 \mathrm{~g} / \mathrm{l}$, whereas the lower tannic acid concentration $(0.040$ $\mathrm{g} / \mathrm{l})$ increased nematode egg hatch. In all in vitro experi- 

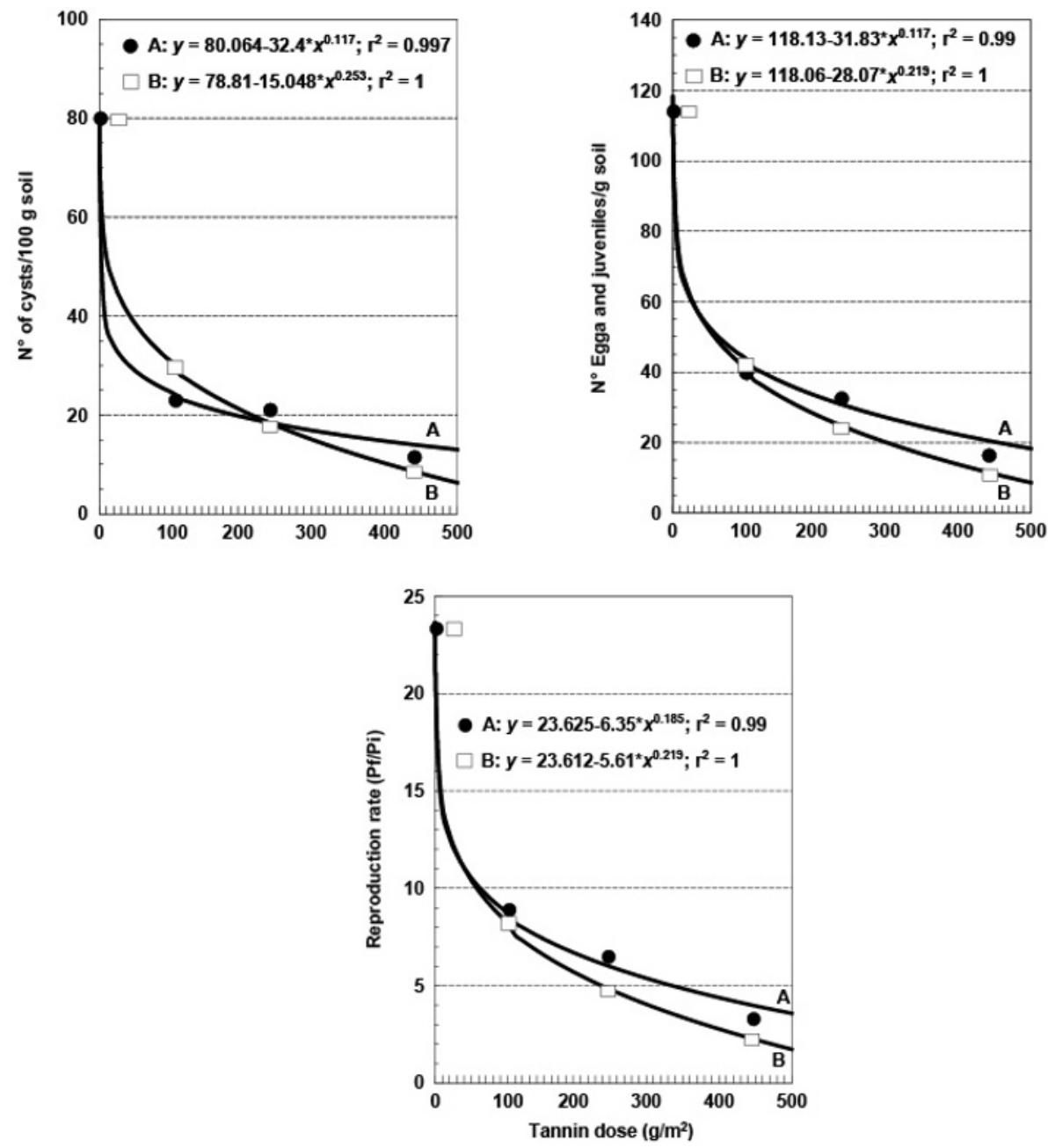

Fig. 1. Relationship between doses of soil applied tannin aqueous solution and number of cysts/100 g soil, eggs and juveniles/g soil and reproduction rate of G. rostochiensis (Ro1).

Each experimental point represents the average of four replicates. Lines A and B represent the predicted function calculated by fitting experimental data to different equations and relative to tannin application at transplant and to tannin applications at transplant and two weeks later, respectively.

ments, including also this experiment, percent egg hatch significantly decreased with the increase of tannin concentrations and with longer exposure times, which are probably the most important factors involved in nematode suppression.

Results from glasshouse experiment showed no effect on stimulation of potato plant growth parameters (top fresh and dry stem and root weights and stem height) compared with the untreated control, and treatments with the highest dose of tannin $\left(450 \mathrm{~g} / \mathrm{m}^{2}\right)$ applied at sowing and at sowing and 2 weeks later showed a considerable phytotoxicity on potato plants. These findings are in agreement with that found by Mian and Rodríguez-Kábana (1982) or Hewlett et al. (1997), on other crops, where the use of higher amount of tannins showed phytotoxic effect on growth parameters of squash and tomato plants, respectively. Some residues of plants contain volatile fatty acids (VFAs) and phenolic compounds (PCs) which are phytotoxic on other plant species growth as found by Wanniarachchi and Voroney (1997). They tested the release of VFAs and PCs from root, stem and leaves residues of canola plants (rape- seed) (Brassica napus L.) and their inhibiting ( $\mathrm{P} \leq 0.01)$ effect on seedling growth (coleoptile and radicle lengths) of corn (Zea mays L.), barley (Hordeum vulgare L.) and wheat (Triticum aestivum L.) plants. Toxicity of residue extracts was not related to the amounts of VFAs and PCs found. However, toxicity appeared to be most related to the presence of total phenolic compounds in the residue extracts.

In contrast, on tomato plants grown in soil infested with root-knot nematode Meloidogyne javanica, Maistrello et al. (2010) found no phytotoxic effect on plant growth of chestnut tannin at rate of $450 \mathrm{~g} / \mathrm{m}^{2}$ as used in our experiment on potato.

In the pot experiment all doses of chestnut tannin $(100,250$ and $450 \mathrm{~g} / \mathrm{m}^{2}$ ) significantly reduced the number of cyst $/ 100 \mathrm{~g}$ soil, number of eggs and $\mathrm{J}_{2} / \mathrm{g}$ soil and the reproduction rate " $r$ " in comparison to untreated soil (control). This agrees with results from Maistrello et al. (2010) where the same chestnut tannin, applied at the same doses, significantly reduced the number of eggs and $\mathrm{J}_{2} / \mathrm{g}$ root, the final nematode population density $/ \mathrm{cm}^{3}$ soil and the " $r$ " of 
Meloidogyne javanica on tomato plants. Similarly, in a field experiment on squash, also Mian and RodríguezKábana (1982) recorded Meloidogyne arenaria suppression after tannic acid treatments. Taylor and Murant (1966) found a reduction of number of Longidorus elongatus (de Man) in soil treated with two powdered tannin extracts from mimosa (Acacia mollisima Willd.) and quebracho (Schinopsis lorentzii (Griseb.) Engler). Moreover, L. elongatus is a virus vector of plant soil borne viruses which were previously suppressed by adding tannins to the soil (Cadman \& Harrison, 1960). Considering that these viruses are not free in the soil ut they are transmitted by L. elongatus, Tylor and Murante (1966) hypothesized that viruses plant protection was obtained by the control of the vector virus and not by the direct effect of tannin on the virus.

Results from the pot experiment might be due to a double effect of tannin solutions: a) the nematicidal effect as confirmed in the hatching test and b) to the repellent action towards to $G$. rosatochiensis juveniles.

Application of repellents at sowing, planting or before transplant, may serve to disorientate plant parasitic nematodes causing them difficulties in locating the root systems and potentially reducing nematode attack as previously found by Hewlett et al. (1997) for Radopholus similis and Maistrello et al. for M. javanica (2010).

In the pot experiment, a significant reduction of the nematode population was obtained by the use of all tannin doses and no significant differences were observed between the two application times, at sowing and at sowing and 2 weeks later, at the same rate $\left(100,250\right.$ and $\left.450 \mathrm{~g} / \mathrm{m}^{2}\right)$, demonstrating the positive effect of only one application of the tannin solution. Based on our results it seems that the best application rate is $250 \mathrm{~g} / \mathrm{m}^{2}$ applied at sowing because of at this dose of chestnut tannin it is possible to obtain on potato the highest nematicidal effect without phytotoxicity. These results are in agreement with those found by Maistrello et al. (2010) which reported that the best suppression of $M$. javanica nematode population was obtained at the dose of $250 \mathrm{~g} / \mathrm{m}^{2}$ of tannin applied at transplant and no phytotoxicity was shown at all doses tested (100, 250 and $450 \mathrm{~g} / \mathrm{m}^{2}$ ).

Data from glasshouse experiment on the same population of the potato cyst nematode $G$. rostochiensis, patotype Ro1, confirm results obtained in the in vitro experiment.

In conclusion, the use of tannins from chestnut seems to be a promising control method of potato cyst nematodes in sustainable agriculture. However, further studies are suggested to investigate the effect of tannins derived from different plants (chestnut, quebracho, mimosa etc.), in different types of soils, on different nematode species and on beneficial soil free living nematodes.

\section{Acknowledgements}

The research was undertaken within the framework of a bilateral project between the Italian National Council of Research (CNR) and the Slovak Academy of Sciences (SAS) $(2010$ - 2012). The authors acknowledge the sup- port of the scientific grant agency VEGA (Grant $\mathrm{N}^{\circ}$ 2/0136/10) and (Grant $\left.\mathrm{N}^{\circ} 2 / 0147 / 10\right)$ and Dr. Sebastiano Laquale for technical assistance.

\section{References}

Аввотт, W. S. (1925): A method of computing the effectiveness of an insecticide. J. Econ. Entomol., 18: 265 - 267 Aires, A., Carvalho, R., Da ConceiçaO, M., Eduardo, R. (2009): Suppressing potato cyst nematode, Globodera rostochiensis, with extracts of Brassicacea plants. Am. J. Pot. Res., 86: 327 - 333. DOI: 10.1007s12230-009-9086-y Anand, S.C., Cook, R., Dale, M.F.B. (1998): Development of resistant and tolerant varieties. In: SHARMA S.B. (Ed.) The cyst nematodes. Chapman \& Hall, London, U.K., pp. $293-320$

BeEn, T. H., SchOMAKeR, C. H. (1999): Fumigation of marine clay soils infested with Globodera pallida and $G$. rostochiensis using 1,3-dichloropropene and additional top soil treatments. Nematology, 1: 3 - 14. DOI: 10.1163/15685 4199507929

Cadman, C. H., Harrison, B. D. (1960): Studies on the behaviour in soils of tomato black ring, raspberry ringspot and arabic mosaic viruses. Virology, 10: $1-20$

Cespedes, C. L., Avila, J. G., Marin, J. C., Dominguez, M. L., TORRES, P., ARANDA, E. (2006): Chapter 1. Natural compounds as antioxidant and molting inhibitors can play a role as a model for search of new botanical pesticides. In: RAI and CARPINELla (Eds.). Naturally Occurring Bioactive Compounds. Vol. 3: 1 - 27. DOI 10.1016/S1572-557X (06)03001-7

Chen, S., Dickson, D.W., Hewlett, T.E. (1997): Tannic acid effects on hatching of Heterodera glycines in vitro. $J$. Nematol. 29: $742-745$

CHITwOoD, D. J. (2002): Phytochemical based strategies for nematode control. Ann. Rev. Phytopathol., 40: 221 249. DOI: 10.1146/annutev.phyto.40.032602.130045

D’Addabbo, T., Papajova, I., SASANelli, N., Radicci, V., RENČO, M. (2011): Suppression of root-knot nematodes in potting mixes amended with different composted biowastes. Helminthologia, 48 (4), 278 - 287. DOI: 10.2478/ S11687-011-0039-X

EKANAYAKE, H. R. M. K., DI VITO, M. (1984): Influence of root leachates and temperatures on egg hatch of Meloidogyne species. Nematol. Mediterr., 12: $119-127$

Elizondo, A.M., Mercado, E.C., RabinOvitz, M.C., FERNANDEZ-MIYAKAWA, M.E. (2010): Effect of tannins on the in vitro growth of Clostridium perfringens. Vet. Microbiol., 145: 308 - 314. DOI: 10.1016/j.vetmic.2010.04.003

FEENY, P. (1976): Plant apparency and chemical defence. Recent Adv. Phytochem., 10: 1 - 40

Greco, N., Di Vito, M., Brandonisio, A., Giordano, I., DE MARINIS, G. (1982): The effect of Globodera pallida and Globodera rostochiensis on potato yield. Nematologica, 28: $379-386$

Greco, N., Brandonisio, A., Bultrini, A. (1984): Control of Globodera rostochiensis on potato with fumigant and non fumigant nematicides. Nematol. Mediterr., 12: 7 - 13 
Hewlett, T. E., Hewlett, E. M., Dickson, D. W. (1997): Response of Meloidogyne spp., Heterodera glycines and Radopholus similis to Tannis Acid. J. Nematology, 29: 737 $-741$

Hoste, H., Jackson, F., Athanasiadou, S., Thamsborg, S. M., Hoskin, O. S. (2006): The effects of tannin-rich plants on parasitic nematodes in ruminants. Trends Parasitol., 22: 253 - 261. DOI: 10.1016/j.pt.2006.04.004

HU, C., QI, Y.C. (2010): Abundance and diversity of soil nematodes as influenced by different organic manure. Helminthologia, 47: 58 - 66. DOI: 10.2478/s11687-0100009-8

Maistrello, L., VACCARi, G., SASAnelli, N. (2010): Effect of chestnut tannins on the root-knot nematode Meloidogyne javanica. Helminthologia, 47: 48 - 57. DOI: 10.2478/s11687-010-0008-09

MCSORLEY, R., MCGOVERN, R. J. (2000): Effect of solarization and ammonium amendments on plant-parasitc nematodes. J. Nematol., 32(4S): $537-541$

MiAn, I.H., RODRÍGUEZ-KÁBANA, R. (1982): Organic amendments with high tannnin and phenolic contents for control of Meloidogyne arenaria in infested soil. Nematropica, 12: $221-234$

NGUYENA, T.M., BINH, D.V., ØRSKOV, E.R. (2005): Effect of foliages containing condensed tannins on gastrointestinal parasites. Anim. Feed Sci. Tech., 121: 77-87

O'DONOVAN, L., BroOKER, J.D. (2001): Effect of hydrolysable and condensed tannins on growth, morphology and metabolism of Streptococcus gallolyticus (S. caprinus) and Streptococcus bovis. Microbiology, 147: 1025 - 1033

Paolini, V., Bergeaud, J. P., Grisez, G., Prevot, F., Dorchies, PH., Hoste, H. (2003): Effects of condensed tannins on goats experimentally infected with Haemonchus contortus. Vet. Parasitol., 113: 53 - 261. DOI: 10.1016/ S0304-4017(03)00064-5

RenČo, M., D’AdDabbo, T., Sasanelli, N., Papajova I. (2007): The effect of five composts of different origin on the survival and reproduction of Globodera rostochiensis. Nematology, 9(4): 537 - 543.

RenČO, M., SASANElli, N., KovÁČIK, P. (2011): The effect of soil compost treatments on potato cyst nematodes Globodera rostochiensis and Globodera pallida. Helminthologia, 48: 184 - 194. DOI: 10.2478/s11687-011-0027-1

RYAN, A., JONES, P. (2004): The effect of mycorrhization of potato roots on the hatching chemicals active towards the potato cyst nematodes, Globodera pallida and G. rostochiensis. Nematology, 6: 335 - 342. DOI: 10.1163/15685

\section{6}

Sasanelli, N., Di Vito, M. (1991): The effect of Tagetes spp. on the hatching of an Italian population of Globodera rostochiensis. Nematol. Mediterr., 19: 135 - 137

SASANELli, N., D'ADDABBO, T. (1992): The effect of Cineraria maritima, Ruta graveolens and Tagetes erecta extracts on the hatching of Heterodera schachtii. Nematol. Mediterr., 20: 49 - 51

SASANELLI, N. (1994): Tables of nematode-pathogenicity. Nematol. Mediterr., 22: 153 - 157

Sasanelli, N., Attila, A., D'AdDabBo, T., TAKacs, T. (2007): Nematicidal properties of leaf extracts of Ruta graveolens inoculated with arbuscular mycorrhizal fungi. Russ. J. Nematol. 15: 65-73

Sasanelli, N. Anton, A., Takacs, T., D’AddabBo, T., BirO, I., MALOV, X. (2009): Influence of arbuscular mycorrhizal fungi on the nematicidal properties of leaf extracts of Thymus vulgaris L. Helminthologia, 46: 230 240. DOI: 10.2478/s11687-009-0043-6

SCALBERT, A. (1991): Antimicrobial properties of tannins. Phytochem., 30: 3875 - 3883

SeInHORst, J. W., Den Ouden, H. (1966): An improvement of Bijbloo's method for determining the egg content of Heterodera cysts. Nematologica, 12: 170 - 171

SPHEPHERD, A. M. (1986): Extraction and estimation of cyst nematodes. In SOUTHEY J. F. (Ed.). Laboratory methods for work with Plant and Soil nematodes. London, Her Majesty's Stationary Office. Ministry of Agriculture, Fisheries and Food. pp. $31-50$

TAYlOR, C. E., Murant, A. F. (1966): Nematicidal activity of aqueous extracts from raspberry canes and roots. Nematologica, 12: 488 - 494

Toden, T. C., Korthals, G. W., Termorshuizen, A. J. (2011): Organic amendments and their influences on plantparasitic and free-living nematodes: a promising method for nematode management? Nematology, 13: 133 - 153. DOI: org.10.1163/138855410X541834

Waghorn, G. C., MCNABB, W. C. (2003): Consequences of plant phenolic compounds for productivity and health of ruminants. Proc. Nutr. Soc., 62: $383-392$

Wanniarachchi, S. D., Voroney, R. P. (1997): Phytotoxicity of canola residues: Release of water-soluble phytotoxins. Can. J. Soil Sci., 77: 535 - 541

WATERMAN, P. G. (1999): The tannins - an overview. In: BROOKER J. D. (Ed) Tannins in livestock and human nutrition. Adelaide, Australian Centre for International Agricultural Research, Australia, pp. $10-13$ 